\title{
Growth of tin catalyzed silicon nanowires by electron beam evaporation
}

\author{
R. Rakesh Kumar ${ }^{\star}$, K. Narasimha Rao ${ }^{1}$, K. Rajanna ${ }^{1}$, A. R. Phani ${ }^{2}$ \\ ${ }^{1}$ Department of Instrumentation and Applied Physics, Indian Institute of Science, Bangalore 560012, India \\ ${ }^{2}$ Nano-Research for Advanced Materials and Technologies, Banglore 560040, India
}

*Corresponding author. Tel: (+91) 802293 3190; Fax: (+91) 802360 0135; E-mail: rakeshr@iap.iisc.ernet.in

Received: 28 March 2013, Revised: 29 April 2013 and Accepted: 01 May 2013

\section{ABSTRACT}

Silicon nanowires were grown on tin $(\mathrm{Sn})$ coated $\mathrm{Si}$ substrates using electron beam evaporation technique at a growth temperature of $350^{\circ} \mathrm{C}$. The as grown Si nanowires were characterized by Field Emission Scanning Electron Microscope (FESEM), Transmission Electron Microscopy attached with Energy Dispersive X-Ray Analyser (TEM-EDX) for their morphological, structural, and compositional properties, respectively. The grown Si nanowires were randomly oriented on the substrate with a length of $\sim 500 \mathrm{~nm}$ for a deposition time of $15 \mathrm{~min}$. Silicon nanowires have shown tin nanoparticle (capped) on top of it confirming the Vapor-Liquid-Solid (VLS) growth mechanism responsible for Si nanowires growth. The nanowire growth rate was measured to be $\sim 30 \mathrm{~nm} / \mathrm{min}$. Transmission Electron Microscope (TEM) measurements have revealed single crystalline nature of Si nanowires. The obtained results have indicated good progress towards finding alternative catalyst to gold for the synthesis of Si nanowires. Copyright (C) 2013 VBRI press.

Keywords: Semiconductors; Si nanowires; electron beam evaporation; VLS growth mechanism; Sn catalyst; thin films.

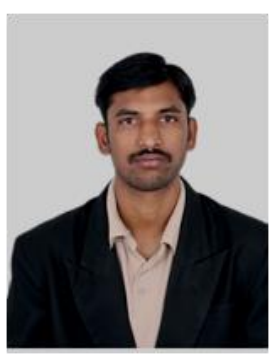

R. Rakesh Kumar received his M.Sc Degree in Electronics and Instrumentation from University College of Science, Osmania University, Hyderbad, India. Presently he is pursuing his Ph.D from Department of Instrumentation and Applied Physics, Indian Institute Of Science (IISc), Bangalore, India. His Research Interest includes Nanowires synthesis and their applications. He has 10 international publications on nanowires.

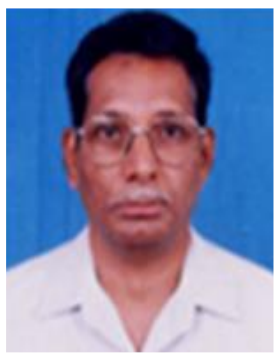

K. Narasimha Rao received his Ph.D (Thin films) from Department of Instrumentation and Applied Physics, Indian Institute of Science (IISc), Bangalore, India. Presently, he is a Chief Research Scientist in the same department. His field of research Optical Coatings, Nanostructures synthesis.

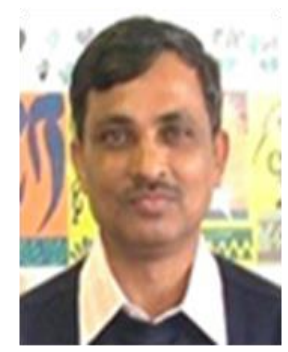

K. Rajanna received his Ph.D. (1993) from Department of Instrumentation and Applied Physics, Indian Institute of Science (IISc), Bangalore, India. Presently, he is a Professor and Chairman of the same department. His field of research covers gas sensors, radiation sensor, development of piezo-materials based sensors and MEMS.

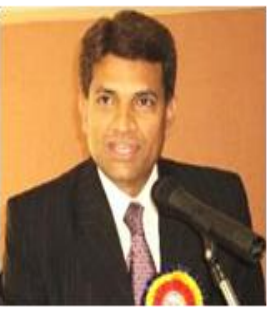

A.R. Phani received his Ph.D in Materials Chemistry from Indian Institute of Chemical Technology, Hyderabad, India. He has more than 180 international publications and filed 4 patents. He is Managing Director for Nano Research for Advanced Materials Technologies (www.nano-ram.org, www.nanoram.co.in), Bangalore and also chief scientist in Mazumdar Shaw Cancer Center, Narayana Hyrudayalaya Hospitals, Bangalore, India. He is also visiting professors in 6 Indian and 4 International Universities.

\section{Introduction}

The Vapour-Liquid-Solid (VLS) method is one of the most common synthesis used for Si nanowires (NWs) growth, which has been first proposed by Wagner and Ellis in 1964 [1]. In their investigation, a metal catalyst droplet has been alloyed and supersaturated with Si resulting in precipitation and an axial growth of nanowire beneath the droplet. The successful growth of Si NWs mainly relies on the use of gold $(\mathrm{Au})$ as a catalyst [2, 3]. Although gold has several advantages such as good thermal stability, and chemical inertness, and can be deposited easily, attention has been given to alternate catalyst for $\mathrm{Si}$ NWs growth due to three different reasons [4-7]. First, $\mathrm{Au}$ is incorporated into the NWs during growth [7]. Since Au is a deep level impurity in semiconductors $(\mathrm{Si}, \mathrm{Ge})$ that degrades the optical and 
electronic properties [8, 9]. Optical and electronic properties of NWs grown with alternate catalyst could be improved in principle $[\mathbf{1 0}, \mathbf{1 1}]$. Second, nanowires growth with alternate catalyst can be done at low temperatures [1214] when compared with the Au catalyzed NWs growth [2, 3]. This low temperature growth can be useful in microelectronic device fabrication. Third, high solubility of $\mathrm{Si}, \mathrm{Ge}$ in $\mathrm{Au}$ does not result in abrupt hetro structures $(\mathrm{Si} / \mathrm{Ge}$ or $\mathrm{Si} / \mathrm{GeSi})$ due to reservoir effect $[4,15]$. The abrupt hetro structures can be possible with alternate catalysts due to low $\mathrm{Si}$ solubility in alternate catalyst [4, 16]. It is for this reason that an alternative metal to gold has been investigated for the synthesis of semiconductor NWs [4-6]. From this point of view, Tin ( $\mathrm{Sn}$ ) can be used as an alternative candidate because of its low eutectic point $\left(232^{\circ} \mathrm{C}\right)$ [17], low solubility of $\mathrm{Si}$ in $\mathrm{Sn}$. Synthesis of $\mathrm{Si}$ NWs employing tin (Sn) as a catalyst has been recently achieved with the plasma enhanced CVD [14, 18-21], supercritical fluid-liquid-solid (SFLS) [22] and Hydrogen radical assisted methods [23-25]. Recently, we have reported the growth of the Si NWs with alternate catalysts such as Indium (In), Bismuth (Bi) at low substrate temperatures of $280^{\circ} \mathrm{C}$ and $300^{\circ} \mathrm{C}$ respectively by e-beam evaporation method (EBE) $[\mathbf{1 2}, \mathbf{2 6}]$. The advantages of ebeam evaporation are found elsewhere [2]. In the present investigation, the same method was now employed using $\mathrm{Sn}$ as a catalyst.

In the present investigation, we report the growth of $\mathrm{Si}$ NWs using tin ( $\mathrm{Sn}$ ) as a catalyst by EBE at a low substrate temperature of $300-350^{\circ} \mathrm{C}$. For the first time, we are reporting the growth of the silicon nanowires with tin catalyst by EBE. As-grown nanowires were characterized by Field Emission Scanning Electron Microscope (FESEM), X-Ray Diffraction (XRD) and Transmission Electron Microscope (TEM) for their morphological and structural properties, respectively. The growth of Si NWs by EBE method using $\mathrm{Sn}$ catalyst can be further implemented with other alternate catalyst such as $\mathrm{Ga}$ as well.

\section{Experimental}

\section{Materials}

Silicon ingots (Balzers, 99.99\%, USA) were used for $\mathrm{Si}$ nanowires growth. Tin ingots (Alfa Aesar, 99.99\%, USA) were used for catalyst layer deposition. p-type Si (100) substrates (Silicon Valley Microelectronic, USA) were used as a substrates.

\section{Methods}

The experimental set up and experimental procedure of $\mathrm{Si}$ NWs growth with Sn catalyst is similar to the previous reports $[\mathbf{1 2}, \mathbf{2 6}]$ (See supplementary information). Pure Si ingots $(99.99 \%$ Blazers) loaded into a water cooled graphite crucible have been used as a source for e- beam evaporation. p-type $\mathrm{Si}(100)$ wafers have been cleaned in an ultrasonic bath with acetone, followed by a (5\%) dilute hydrofluoric acid (HF) solution for $3 \mathrm{~min}$ to remove the native oxide layer and then rinsed with de-ionised (DI) water, followed by isopropyl alcohol and finally blown dry with $\mathrm{N}_{2}(99.999 \%)$ before loading in to e-beam chamber. E- beam chamber has been evacuated to a vacuum of $1 \times 10^{-5}$ mbar using a diffusion and rotary pump combination. Initially, Sn thin film of thickness $20 \mathrm{~nm}$ is deposited on to the $\mathrm{Si}$ substrates by Resistive thermal evaporation of $\mathrm{Sn}$ at room temperature at a vacuum of $1 \times 10^{-5} \mathrm{mbar}$. Without breaking the vacuum, Sn coated Si substrates have been annealed at growth temperature for $5 \mathrm{~min}$ prior to the $\mathrm{Si}$ NWs growth to get Sn catalyst droplets. The growth of Si NWs carried in a temperature window of $200-500{ }^{\circ} \mathrm{C}$ for a deposition time of $15 \mathrm{~min}$ at $\mathrm{Si}$ evaporation rate of 0.2 $\mathrm{nm} / \mathrm{s}$.

\section{Characterization}

The morphology of the grown Si NWs, formed Sn catalyst particles was examined by a Field Emission Scanning Electron Microscope (FESEM, FEI Sirion). Crystallinity of the Sn thin film was examined by X-Ray diffraction (XRD, D8 advacnce Bruker), the microstructure and compositional properties of the nanowires were characterized by Transmission Electron Microscopy (FEI, T-20).

\section{Results and discussion}

\section{Characterization of tin nanoparticles}

Fig.1(a) shows the formed tin catalyst particles on the $\mathrm{Si}$ substrate after annealing of the $20 \mathrm{~nm}$ Sn catalyst film at a temperature of $350^{\circ} \mathrm{C}$ for $5 \mathrm{~min}$. Silicon substrate surface has been uniformly covered by spherical tin droplets with a diameter in the range of 30-100nm. This formed Sn catalyst droplets used as a catalyst for Si NWs synthesis. Fig. 1 (b) shows the X-Ray diffraction pattern of Sn thin film deposited on $\mathrm{Si}$ substrates. The diffraction peaks at $2 \theta=30.68,32.06$ have been identified as the (200), (101) planes of the tetragonal crystal structure of Sn, which are very well coincided with JCPDS no. 04-0673.
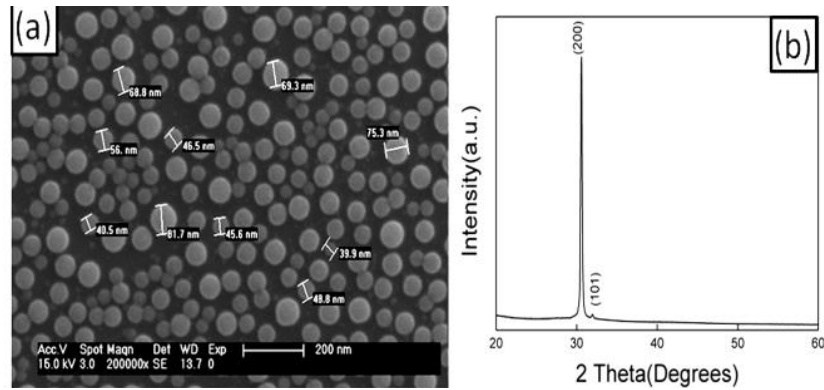

Fig. 1 (a) SEM image (b) XRD pattern of tin (Sn) nanoparticles formed on the $\mathrm{Si}(100)$ substrate at $350{ }^{\circ} \mathrm{C}$ substrate temperature for $5 \mathrm{~min}$.

\section{Characterization of silicon nanowires}

Silicon NWs grown on Si substrates at different substrate (growth) temperatures of $300-480^{\circ} \mathrm{C}$ for 15 minutes have been shown in Fig. 2 (a-d). No nanowire growth was observed on the bare $\mathrm{Si}$ substrates, eliminating the possibility of catalyst independent NWs growth. Nanowires growth was not observed below the eutectic temperature $\left(231^{\circ} \mathrm{C}\right)$ according to the VLS growth procedure [1]. Upon increasing growth temperature above the $230{ }^{\circ} \mathrm{C}$, initiation of nanowires growth observed (for brevity it is not shown in here). This (poor) nanowires growth behaviour is due to 
slow absorption and diffusion of $\mathrm{Si}$ atoms into the $\mathrm{Sn}$ catalyst at temperature less than $300^{\circ} \mathrm{C}$. Nanowires growth in the temperature range of $300-350^{\circ} \mathrm{C}$ becomes better and form dense nanowires on the substrates. Grown Si NWs morphology is similar to the reported Si NWs growth with alternate catalysts in the literature $[\mathbf{1 3}, \mathbf{1 4}, \mathbf{2 7}, \mathbf{2 8}]$. These NWs have been randomly oriented with respect to the substrate, and each nanowire has tin ( $\mathrm{Sn}$ ) catalyst particle at its top and growth temperature is well above the eutectic temperature confirming the VLS growth of Si NWs [6]. High resolution FESEM images of the Si NWs grown at $350{ }^{\circ} \mathrm{C}$ shown in the Fig. 2 (e-f) (See supplementary material).

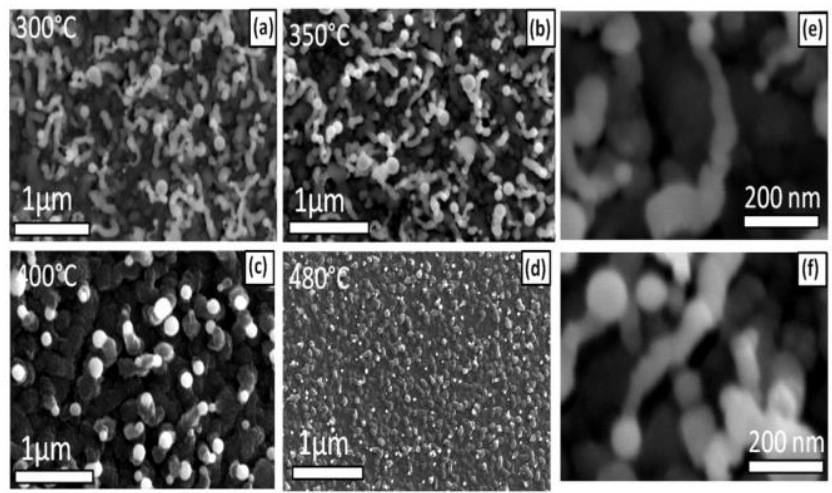

Fig. 2. SEM images of $\mathrm{Si}$ nanowires grown on tin nanoparticles as nucleation growth at different growth temperatures of (a) 300 (b) 350, (c) 400, (d) $480^{\circ} \mathrm{C}$. (e)-(f) High resolution SEM image of the Si NWs (at $\left.350^{\circ} \mathrm{C}\right)$.

These NWs have a length of approximately 500-600 $\mathrm{nm}$. We could not measure accurately the diameter of the nanowires because of the tapering of the NWs. The Si NWs growth rate has been measured and found to be $\sim 30$ $\mathrm{nm} / \mathrm{min}$. From SEM images, the areal density (number of NWs per unit area) has been calculated and is found to be around 2-3 NWs $/ \mu^{2}$. As the growth temperature is increasing from 350 to $400{ }^{\circ} \mathrm{C}$ nanowires growth turned out to be nanorods growth and more un-catalyzed deposition on the nanowires, finally at growth temperature greater than $450^{\circ} \mathrm{C}$ nanowires growth is completely suppressed. This nanowires growth behaviour with temperature is well supported by experimental and theoretical works on nanowires growth by physical vapour deposition (PVD) methods such as EBE and MBE [29, 30]. The nanowires growth is explained by two processes. The evaporated atoms fall on the substrate as well as on the catalyst particle. The atoms which fall on the catalyst particle eventually supersaturate and precipitate as a nanowire according to the VLS principles. The atoms which fall on the substrate and nanowires sidewalls will diffuse towards the catalyst particle and contribute to the nanowire growth [29]. The adatoms contribution to the nanowire growth is a temperature dependent phenomenon. Nanowires length is increases with temperature $\left(300-350{ }^{\circ} \mathrm{C}\right)$ initially due to increased diffusion of ad atoms that contribute to the axial growth. As temperature increases $\left(350-450{ }^{\circ} \mathrm{C}\right)$, adatoms contribution to the nanowires gradually decreases results in thin film (2D) deposition dominates over the nanowires (axial) growth. This was clearly evidenced in the Fig. 2(d). The advantage of current approach of $\mathrm{Sn}$ catalyzed $\mathrm{Si}$ nanowires is simple process, cost effective and low temperature growth of Si nanowires compared to the other methods such as hydrogen radical assisted method [23,25], plasma enhanced CVD [14, 21] (see supplementary material). In hydrogen radical assisted method, plasma enhanced CVD additional plasma pre-treatment is required to get Sn catalyst particles but in the current report no such treatment is required. High vacuum deposition of catalyst layer in the present report is useful for avoiding the oxidation of catalyst layer. Avoiding the catalyst layer oxidation is greatly enhances the nanowires growth probability.

Bright filed TEM image of a single $\mathrm{Si}$ nanowire grown by $\mathrm{EBE}$ at substrate temperature of $350^{\circ} \mathrm{C}$ for $15 \mathrm{~min}$ has been shown in Fig. 3(a). It has been clearly identified in Fig 3(a) that tin nanoparticle located at the end of (capped) the $\mathrm{Si}$ nanowire, implying that a tin $(\mathrm{Sn})$ catalyst assisted VLS mechanism growth in Si NWs formation. The High resolution TEM recorded over the nanowire has clearly shown a high degree of crystallinity with a clear crystal lattice as shown in Fig 3 (b). The lattice spacing in the HRTEM in Fig. 3(b) has been found to be $0.31 \mathrm{~nm}$, which corresponds to the "d" spacing of the (111) plane of Si.

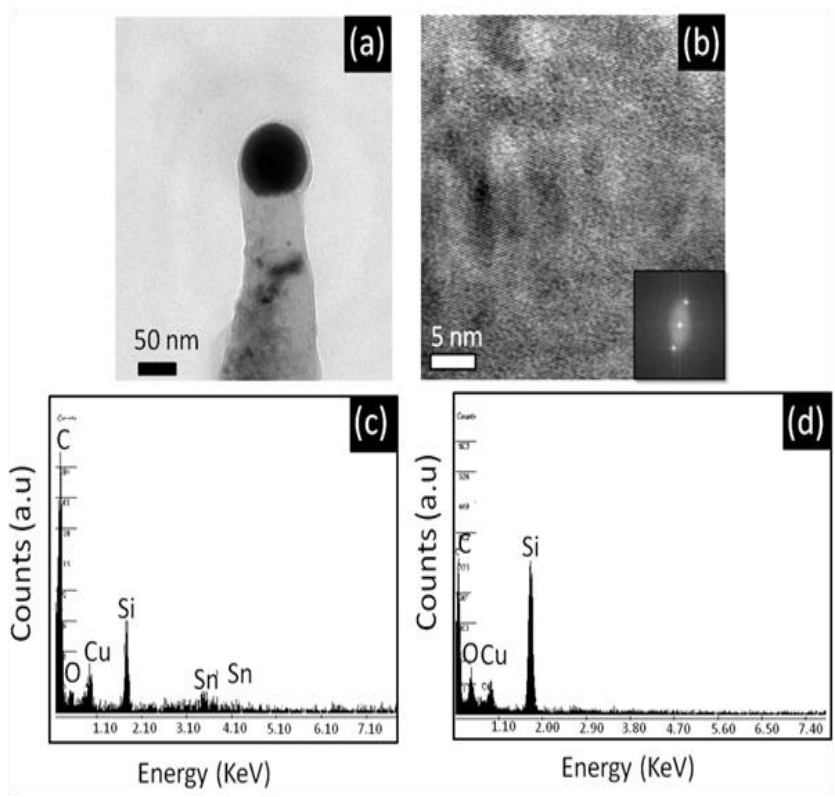

Fig. 3. (a) TEM image of the single Si nanowire, (b) HRTEM recorded on the Si nanowire (inset FFT pattern), (c) EDX spectrum recorded on the catalyst particle and (d) EDX spectrum recorded on the nanowire.

EDX spectra recorded on the Si NWs at the tip and the stem of the Si NWs during analysis have been shown in Fig. 3 (c) and (d), respectively. The EDX spectra have revealed that the tip of the nanowire contains both $\mathrm{Si}$ and $\mathrm{Sn}$, whereas the base or stem of the nanowire contains only $\mathrm{Si}$. The other peaks, such as $\mathrm{Cu}$ and $\mathrm{O}$, have also been detected attributing to the effect of TEM grid $(\mathrm{Cu}, \mathrm{O})$ and also oxide layer formed on the as grown $\mathrm{Si}$ NWs due to exposure of sample to the atmosphere during sample preparation. These results have indicated that the assynthesized Si NWs by e- beam evaporation technique are single crystalline in nature without any impurities. 


\section{Conclusion}

Tin catalyzed Si NWs were grown by the electron beam evaporation method under a high vacuum $\left(1 \times 10^{-5} \mathrm{mbar}\right)$ on a Si substrate at a temperature of $300-350^{\circ} \mathrm{C}$. FESEM studies show that the grown nanowires were randomly oriented with respect to the substrate, having an average length of $500-600 \mathrm{~nm}$. Each NW is capped with a tin nanoparticle and growth temperature well above the eutectic temperature confirming the VLS growth of the Si NWs and the nanowires growth rate was measured to be $30 \mathrm{~nm} / \mathrm{min}$. The TEM study on the nanowires shows that the grown nanowires were single crystalline in nature. It is observed that a narrow temperature window from $300^{\circ} \mathrm{C}$ to $350^{\circ} \mathrm{C}$ for the Si nanowires growth with Sn catalyst.

\section{Acknowledgements \\ The authors thank the Advance Facility for Microscopy and Microanalysis (AFMM) for providing the microscopy facilities, IISc, Bangalore.}

\section{Reference}

1. Wagner, R. S.; Ellis, W. C. Appl. Phys. Lett. 1964, 4, 89. DOI: $\underline{10.1063 / 1.1753975}$

2. Irrera, A.; Pecora, E. F.; Priolo, F. Nanotechnology. 2009, 20, 135601 .

DOI: $10.1088 / 0957-4484 / 20 / 13 / 135601$

3. Xu, T.; Sulerzycki, J.; Philippe, J.; Patriarche, G.; Grandider, B.; Stevenard, D. Nanoscale. Res. Lett. 2011, 6, 113. DOI: $10.1186 / 1556-276 \mathrm{X}-6-113$

4. Ross, F. M. Rep. Prog. Phys. 2010, 73, 114501 DOI: $10.1088 / 0034-4885 / 73 / 11 / 114501$

5. Ross, F. M.; Wen, C. Y.; Kodambaka, S.; Wacaser, B. A.; Reuter, M. C.; Stach, E. A. Philo. Mag. 2010, 90, 2807. DOI: $10.1080 / 14786431003745583$

6. Schmidt, V.; Witterman, J. V.; Senz, S.; Gosele, U. Adv. Mater. 2009, 21, 2681.

DOI: $10.1002 / \mathrm{adma} .200803754$

7. Hannon, J. B.; Kodambaka, S.; Ross, F. M.; Tromp, R. M. Nature. 2006, $440,69$.

DOI: $10.1038 /$ nature 04574

8. Valdinoci, M.; Colalongo, L.; Pellegrini, A.; Rudan, M. IEEE Transctions. on Electronic. Devices. 1996, 43, 2269.

DOI: $10.1109 / 16.544420$

9. Perraud, S.; Poncet, S.; Noel, S.; Levis, M.; Faucherand, P.; Rouviere, E.; Thony, P.; Jaussaud, C.; Delsol, R. Solar. Energy. Mater. Solar Cells. 2009, 93, 1568.

DOI: $10.1016 /$ j.solmat.2009.04.009

10. Gunawan, O.; Guha, S. Solar. Energy. Mater. Solar Cells. 2009, 93, 1388.

DOI: $10.1016 /$ j.solmat.2009.02.024,

11. Kayes, B. M.; Filer, M. A.; Putnam, M.C.; Kelzenberg, M. D.; Lewis, N. S.; Atwater, H. A. Appl. Phys. Lett. 2007, 91, 103110. DOI: $10.1063 / 1.2779236$

12. Kumar, R. R.; Rao, K. N.; Phani, A. R. Mat. Lett. 2012, 66, 110. DOI: $10.1016 / \mathrm{j}$. matlet.2011.08.064

13. Alet, P. J.; Yu, L.; Patriarche, G.; Palacin, S.; Cabarrocas, P. R. I. J. Mat. Chem. 2008, 18, 5187.

DOI: $10.1039 / \mathrm{b} 813046 \mathrm{a}$

14. Yu, L.; Alet, P. J.; Picardi, G.; Maurin, I.; Cabrrocas, P. R. I. Nanotechnology. 2008, 19, 485605. DOI: $10.1088 / 0957-4484 / 19 / 48 / 485605$

15. Li, N.; Tan, T. Y.; Gosele, U. Appl Phys A: Mater. Sci. Process. 2008, $A 90,591$

DOI: $10.1007 / \mathrm{s} 00339-007-4376-\mathrm{Z}$

16. Wen, C. Y.; Reuter, M. C.; Tersoff, J.; Kodambaka, S.; Stach, E. A.; Ross, F. M. Science. 2009, 326, 1247.

DOI: $10.1126 /$ science. 1178606

17. Olesinski, R. W.; Abbaschian, G. J. Bull. Alloy. Phase. Dia. 1984, 5, 273.

DOI: $\underline{10.1007 / \mathrm{BF} 02868552}$
18. Cho, J.; Donnell, B.O.; Yu, L.; Kim, K. H.; Ngo, I,; Cabarrocas, P. R. I. Prog. Photovolt: Res.Appl. 2013, 21, 77. DOI: $10.1002 /$ pip. 1245

19. Donnell, B. O.; Yu, L.; Foldyna, M.; Cabarrocas, P. R. I. J. Noncrys. Solids. 2012, 358, 2299.

DOI: $10.1016 /$ j.jnoncrysol.2011.11.026

20. Parlevliet, D.; Jennings, P. J. Nanopart. Res. 2011, 13, 4431. DOI: $10.1007 / \mathrm{s} 11051-011-0478-9$

21. Rathi, S. J.; Jariwala, B. N.; Beach, J. D.; Stradins, P.; Taylor, P. C.; Weng, X.; Ke, Y.; Redwing, J. M.; Agarwal, S.; Collins, R T. J. Phy. Chem. C. 2011, 115,3833.

DOI: $10.1021 / \mathrm{jp} 1066428$

22. Chockla, A. M.; Klavetter, K. C.; Mullins, C. B.; Kargel, B. A. Chem. Mater. 2012, 24, 3738. DOI: $10.1021 / \mathrm{cm} 301968 \mathrm{~b}$

23. Jeon, M.; Uchiyama, H.; Kamisako, K. Mater. Lett. 2009, 63, 246. DOI: $10.1016 /$ j.matlet.2008.10.005

24. Jeon, M.; Kamisako, K. Mater. Lett. 2009, 63,777. DOI: $10.1016 / \mathrm{j}$. matlet.2009.01.001

25. Jeon, M.; Kamisako, K. Curr. Appl. Phys. 2010, 10, 5191 DOI: $10.1016 / j . c a p .2009 .11 .056$

26. Kumar, R. R.; Rao, K. N.; Phani, A. R. Ma.t Lett. 2012, 82, 163. DOI: $10.1016 / \mathrm{j}$. matlet.2012.05.090

27. Hernandez, M. J.; Cervera, M.; Ruiz, E.; Pau, J. L.; Piqueras, J.; Avella, M,; Jimenez, J. Nanotechnology. 2010, 21, 455602. DOI: $10.1088 / 0957-4484 / 21 / 45 / 455602$

28. Yu, L.; Donnell, B. D.; Alet, P. J.; Boj, S. C.; Peiro, F.; Arbiol, J.; Cabarrocas, P. R. I. Nanotechnology. 2009, 20, 225604. DOI: $10.1088 / 0957-4484 / 20 / 22 / 225604$

29. Artoni, P.; Pecora, E. F.; Irrera, A.; Priolo, F. Nanoscale. Res. Lett. 2011, $6,162$. DOI: $10.1186 / 1556-276 \mathrm{X}-6-162$

30. Duborovskii, V.G.; Sibirev, N. V.; Cirlin, G. E.; Harmand, J. C.; Ustinov, V. M. Phy. Rev. E. 2006, 73, 021603.

DOI: $10.1103 /$ PhysRevE.73.021603

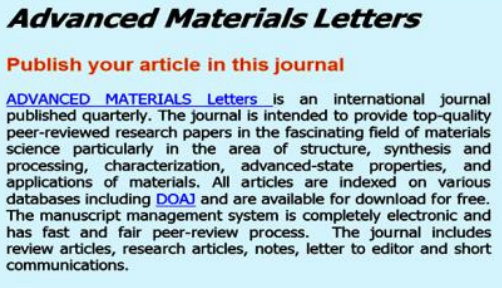
databases including DOs. An articles able for download for free has fast and fair peer-review process. The journal includes
review articles, research articles, notes, letter to editor and shot

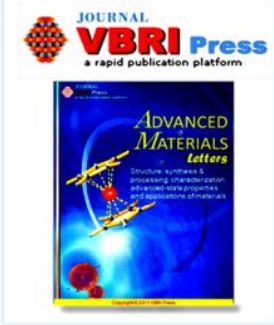




\section{Supporting information}

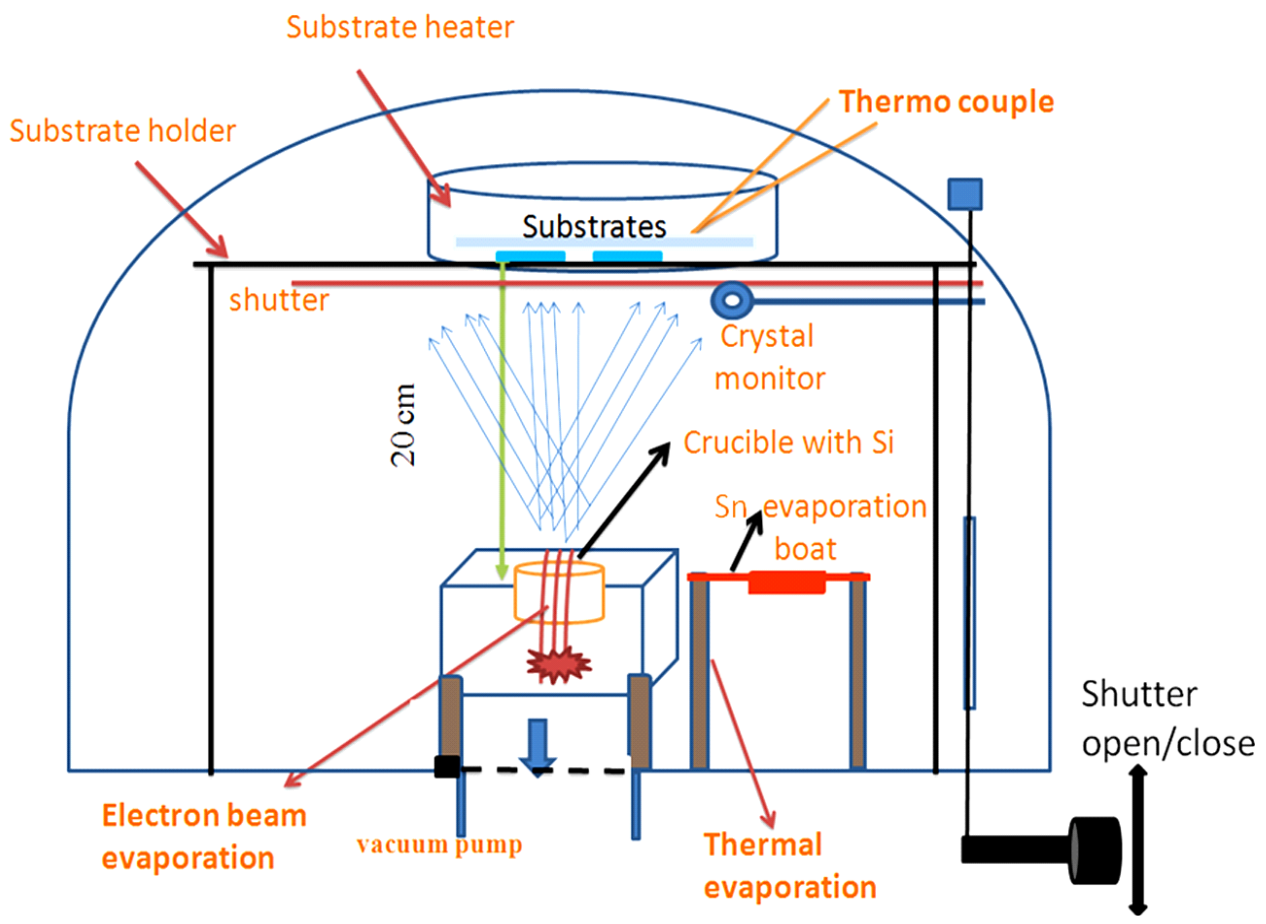

Fig. S1. Schematic of the Si nanowires growth system.
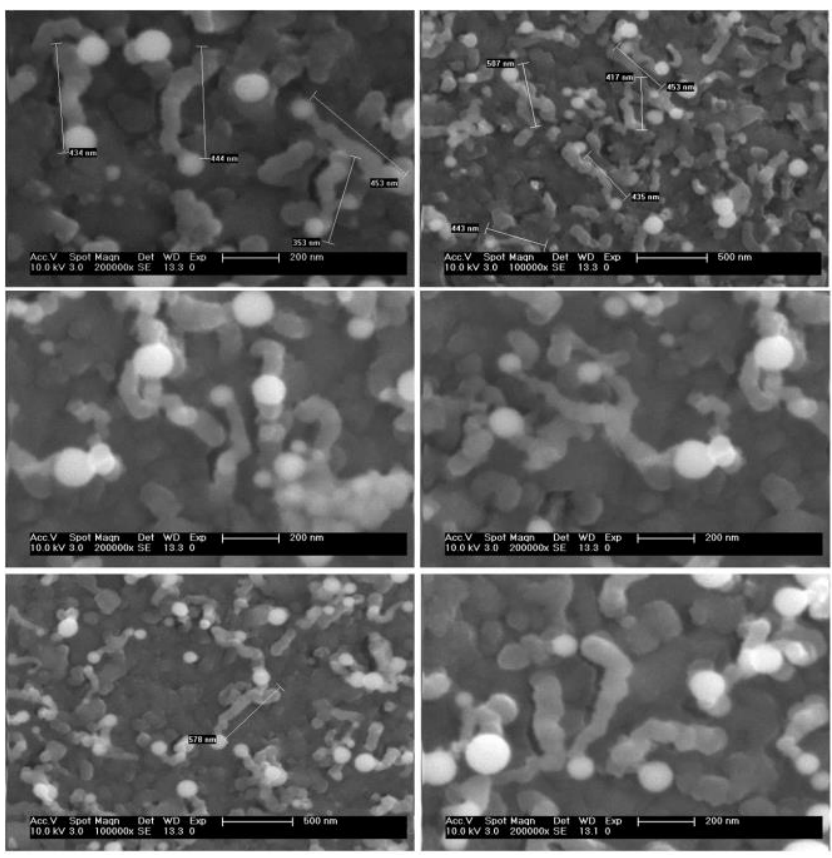

Table S3. Literature review of mostly used method for Si nanowires growth with Sn catalyst.

\begin{tabular}{ccccc}
\hline S.No. & Growth Method & $\begin{array}{c}\text { Growth } \\
\text { temperature }\end{array}$ & $\begin{array}{c}\text { Catalyst film } \\
\text { Pre-treatment }\end{array}$ & Ref. \\
\hline 1. & Hydrogen radical & $400^{\circ} \mathrm{C}$ & $\begin{array}{c}\text { Hydrogen } \\
\text { radical treatment }\end{array}$ & 1 \\
2. & $\begin{array}{c}\text { Hydristed deposition } \\
\text { assisted deposition }\end{array}$ & $400^{\circ} \mathrm{C}$ & $\begin{array}{c}\text { Hydrogen } \\
\text { radical treatment }\end{array}$ & 2 \\
3. & PlasmaEnhanced CVD & $600^{\circ} \mathrm{C}$ & $\begin{array}{c}\text { Plasmatreatment } \\
\text { of catalyst film }\end{array}$ & 3 \\
& & & $\begin{array}{c}\text { Plasmatreatment } \\
\text { of catalyst film }\end{array}$ & 4 \\
4. PlasmaEnhanced CVD & $400^{\circ} \mathrm{C}$ & &
\end{tabular}

Fig S2. High resolution FESEM images of the Si NWs grown at $350^{\circ} \mathrm{C}$. 